\title{
Mechanical and Microstructural Evaluation of Plastically Deformed Brass
}

\author{
Muideen Adebayo Bodude1, Ibrahim Momohjimoh ${ }^{2 *}$, Ruth Nkiruka Nnaji ${ }^{1}$ \\ ${ }^{1}$ Department of Metallurgical and Materials Engineering, University of Lagos, Lagos, Nigeria \\ ${ }^{2}$ Department of Mechanical Engineering, King Fard University of Petroleum and Minerals, Dhahran, \\ Kingdom of Saudi Arabia \\ Email:mbodude@unilag.edu.ng, ‘momhjimoh_ibrahim@yahoo.com,ruthnki@yahoo.com
}

Received 13 October 2015; accepted 18 December 2015; published 21 December 2015

Copyright (C) 2015 by authors and Scientific Research Publishing Inc.

This work is licensed under the Creative Commons Attribution International License (CC BY).

http://creativecommons.org/licenses/by/4.0/

(c) (i) Dpen Access

\begin{abstract}
The mechanical properties as well as microstructure of $\mathrm{Cu}-30.6 \mathrm{wt} \% \mathrm{Zn}$ alloys containing 0.01 wt $\%$ lead has been investigated. The brass alloy was cast and then cold rolled at various percentage reductions: $20 \%, 25 \%, 30 \%, 35 \%$ and $40 \%$ followed by stress relieving annealed at $4500^{\circ} \mathrm{C}$. $\mathrm{Hard}-$ ness, ultimate tensile strength (UTS) and impact toughness values were evaluated at every stage of reduction. It was discovered that the strength, hardness and impact energy all increased with increased percentage reduction. Finally, the optical microscope of the samples was done and the result achieved correlated with the mechanical properties.
\end{abstract}

\section{Keywords}

Brass, Machinability, Microstructure, Cold Rolling, Stress Relieving

\section{Introduction}

Copper and its alloys are widely used in various field of applications due to their excellent mechanical and functional properties and this has made it attractive to industries and researchers. It has been reported that the addition of elements such as zinc, silicon, iron, lead, aluminum and manganese to copper has tremendous effects in improving the mechanical properties [1] [2]. However, the functional properties such as electrical and thermal conductivities reduces when copper is alloyed with other elements due to increase in thermal and interfacial resistance.

Brass has attractive combination of properties such as good corrosion resistant, good wear resistance, high thermal and electrical conductivities which are required in many components of automotive, electrical and valves and fittings [2]. In all of these components, the brasses are usually shaped into semi-finished product by

*Corresponding author. 
means of extrusion, rolling, stamping, cold forming or machining. To increase the machinability of brass, $1 \%$ $3 \%$ lead is usually added to enhance chip fracturing, reduce cutting force, increase the machining rate and ease of productivity, reduce tool wear rate and improve surface finish [3] [4]. The machinability of brasses is improved by addition of lead, sulfur, tellurium and zinc [5] while it deteriorates when tin and iron are added [6] [7]. Brass containing $2 \mathrm{wt} \%$ lead has improved machinability with lead acting as a microscopic chip breaker and tool lubricant, thereby increasing the brittleness of the alloy. The solubility of lead in brass alloys is very low and for that reason it is found in microstructure as dispersed globules within the material. It also acts as a lubricant thereby decreasing the frictional coefficient between the tool and the material, creating discontinuity that enhances chip formation and reducing cutting force and tool wear rate [8] [9].

The global environmental concern on the lead level release in drinking water has call for the need for alternative source for the replacement of lead in leaded brasses. And this has provided an impetus for the development of lead-free brasses [10]. Elements such as bismuth next to lead in the periodic table and with almost the same properties are expected to play the same role of lead in the brass alloys without adverse health effects. Selenium boosts the effect of bismuth, allowing Bismuth concentrations to be used. However, the ductility of brasses containing bismuth and selenium is lower than the conventional leaded brass [11]. According to Michels, [12], the presence of Bismuth at the grain boundaries of copper can cause embrittlement of the copper leading to reduction in ductility of the free-leaded brasses. However, Whiting et al. [8] report that the presence of tin can prevent the segregation of bismuth from the grain boundaries but it is not clear as regards to how the presence of tin prevents the segregation of bismuth.

The deformation characteristics of brass have been studied by Verma et al., [13] and he affirms that higher copper content (larger than 60\%) is needed to produce products by cold working so as to have enough formability. Higher zinc content in the brass promotes brittleness and optimal mechanical properties are display in brass containing $30 \%$ zinc which is characterized by considerable plastic properties together with high tensile strength and hardness [14].

The recrystallization annealing of CuZn30 was studied by Ozgowicz et al., [15] and the increasing temperature of recrystallization annealing within the temperature range of $300^{\circ} \mathrm{C}-650^{\circ} \mathrm{C}$ was found to increase the plastic properties of the brass. The plasticity increases distinctly in this brass after annealing in the range of temperatures from $300^{\circ} \mathrm{C}-400^{\circ} \mathrm{C}$. Also the recrystallization annealing brass with rolling reduction of $15.8 \%$ within the temperature range of $450^{\circ} \mathrm{C}$ to $650^{\circ} \mathrm{C}$ results in a drop of the tensile strength by about $50 \mathrm{MPa}$ and yield strength to about $100 \mathrm{MPa}$ [15]. The hardness of cold rolled brass decreases with decreasing degree of the cold-rolling reduction and the rising temperature of annealing. The brass CuZn30 after cold plastic deformation and recrystallization annealing was found to have fine-gained microstructure of $\alpha$-solution with characteristics twin crystals due to annealing [16] [17].

Stack fault energy (SFE) plays an important role in the plastic deformation of metal alloys. Brass which has FCC structure exhibit low SFE [18] and the stack fault energy decrease rapidly when the zinc content of brass increases. The optical microscopy examination of the shear deformed samples in 70/30 brass showed an absence of any microscale shear bands. Besides, the amount of deformed twinning in the shear band samples was found to be comparable with that in simple compression. Thus twinning and low stack fault energy play a vital role in texture evolution as the low stack fault energy promotes the condition for twinning and twinning in turn promotes increased strain hardening.

Plastic deformation involves the breaking of limited number of atomic bonds by the movement of dislocations. However, the movement of dislocations allows atoms in crystal planes to slip pass one another at much lower stress levels [19]. Several methods of plastic deformations have been invented with the aim of imposing an extremely high plastic strain on the material which result in structural refinement and strength increase without changing the dimensions of the specimens [20]. The microstructure of a material influences the properties of the material and variation in microstructure can significantly change the strength, toughness, hardness, ductility and even thermal and electrical properties [21]. To change the microstructure of a material, a combination of mechanical deformation and heat treatment known as thermomechanical heat treatment may be used. So far, little work has been done on brass containing relatively low percentage of lead and the microstructure influence on the mechanical properties is still a subject of debate as some researchers established that increase reduction in cold rolling reduces the strength and hardness of the brass containing low weight percent of lead.

In this study, as-cast Cu-30.6 wt\% Zn alloy containing $0.01 \mathrm{wt} \%$ lead was subjected to mechanical deformation cold rolling in the reduction range of $20 \%$ to $40 \%$ and then heat treated to a temperature of $4500^{\circ} \mathrm{C}$. The me- 
chanical properties as well as microstructural changes were evaluated.

\section{Material and Method}

\subsection{Material}

The brass sample used was obtained from a local metal market in Owode Onirin, Lagos State Nigeria. The alloycomposition was measured and charged into a crucible furnace and melted. The molten metal was poured into a sand mold to produce $18 \mathrm{~mm}$ diameter brass samples.

\subsection{Cold Roll Deformation and Heat Treatment}

The as-cast cylindrical specimen of $150 \mathrm{~mm}$ length and $18 \mathrm{~mm}$ diameter were cold-rolled with reduction range of $20 \%-40 \%$ (that is, $20 \%, 25 \%, 30 \%, 35 \%$, and $40 \%$ ). The cold-rolled samples were thereafter annealed at $450^{\circ} \mathrm{C}$.

\subsection{Mechanical Testing}

\subsubsection{Tensile Testing}

Tensile tests were carried out using a universal tensile testing machine with a capacity of $25 \mathrm{kN}$ load at the Federal Institute of Industrial Research, Oshodi (FIIRO), Lagos, Nigeria. Specimens for tensile test were machined to a standard shape with a gauge length of $40 \mathrm{~mm}$, total length of $60 \mathrm{~mm}$, gauge diameter of $5 \mathrm{~mm}$ and width of grip section of $10 \mathrm{~mm}$. The tensile test which is a destructive test was applied to the test specimens with increasing tensile force until the material fractured and corresponding readings were recorded. Strain rate of the tensometer was $40 \mathrm{~mm} / \mathrm{min}$.

\subsubsection{Hardness Testing}

Brinell hardness testing was conducted on samples at FIIRO. A load of $5000 \mathrm{~N}$ was applied on the specimen for 10 seconds using $10 \mathrm{~mm}$ ball indenter and the indentation diameter was measured using a digital micrometer screw gauge. The average value was calculated from three measurements considered from different areas on sectioned specimen surfaces. Hardness values was estimated from the diameter of indenter, diameter of indentation and magnitude of applied load by the formula below,

$$
H B=\frac{2 P}{\pi D\left[D-\sqrt{D^{2}-d^{2}}\right]}
$$

where $H B$ is the Brinell hardness number in $\mathrm{kg} / \mathrm{mm}^{2}, D=$ diameter of indentation in $\mathrm{mm}, d=$ diameter of indenter in $\mathrm{mm}, P=$ applied load in $\mathrm{Kg}$.

\subsection{Heat Treatment}

Stress relief annealing was conducted on the samples by heating the as-cast samples to $450^{\circ} \mathrm{C}$ in a muffle furnace and allowing them to cool to room temperature inside the furnace.

\subsection{Microstructural Analysis}

Samples for microstructural analysis were obtained by cutting and sectioning of the heat-treated materials. Sectioned surfaces were ground, polished, with the aid of powder abrasives and etched at the Metallurgy laboratory of University of Lagos, Lagos, Nigeria using the grinding/polishing machine. Polishing was performed using the standard procedure while ferric chloride $\left(\mathrm{FeCl}_{3}\right)$ solution of concentration $0.21 \mathrm{~mol} / \mathrm{dm}^{3}$ was used for etching. The identification of the heterogeneous disperse phases was carried out using the optical metallurgical microscope.

\section{Results and Discussion}

Table 1 shows the weight percentages of the individual elements which make up the brass alloy. It clearly indi- 
Table 1. Weight percentages of different elements present in the brass alloy.

\begin{tabular}{|c|c|c|c|c|c|c|c|c|c|}
\hline $\mathrm{Zn}$ & $\mathrm{Pb}$ & Sn & Mn & $\mathrm{Fe}$ & $\mathrm{Ni}$ & $\mathrm{Si}$ & $\mathrm{Al}$ & C & $\mathrm{Cu}$ \\
\hline 30.60 & 0.01 & 0.003 & 0.002 & 0.024 & 0.001 & 0.015 & 0.035 & 0.004 & 69.03 \\
\hline
\end{tabular}

cated that the brass contains $30 \%$ of zinc which are normally found in brass commercial alloy. The percentage composition of lead in the alloy is relatively low as it is less than $1 \%$ and that implies that the machinability of the alloy will be low as compared to those with relatively high lead content. However, the brass alloy will be environmentally friendly and has global utilization.

\subsection{Mechanical Properties}

\subsubsection{Hardness}

Figure 1 shows the hardness of rolled and stress relieved brass as a function of percentage reduction. It was found that the hardness of the brass increases with increase in the percentage reduction. Also, the rolled brass has higher hardness value than the rolled and stress relieved with the same amount of reduction. This is expected as percentage reduction involved cold working of the metal which generate dislocations within the crystal of the material. The dislocation density increases as the percentage reduction increases and the pile up as well as interaction of the dislocations during deformation results in increasing hardness of the brass alloy. However, stress relieving as thermal reduction in stress involves the rearrangement of dislocations which occurred as a result of mechanical working thereby reducing the dislocation density. It should be noted that the residual stresses which occurred during of cold working of the metal increase the total internal energy of the metallic structure and also the presence of dislocations increases the total internal energy of the structure. This hardness trend is in line with the observation of Askeland and Phule, [22], that the higher the extent of cold working, the higher would be the level of internal energy of the material. Moreover, mechanical rolling involves application of compressive stresses at the surface of the material while the center of the material is under tensile. The higher the level of compressive stresses at the surface, the more the hardness of the material. Again, particle size reduction due to mechanical rolling also contributed to the increase in hardness of the brass alloy as the percentage reduction increases. As reported by Nowosielski, [14], Song et al., [23] higher zinc content (30\%) in combination with higher degree of mechanical deformation can significantly increase the mechanical properties of brass. Thus, increase in dislocation density, high zinc content and particle or grain size reduction due to rolling all contributed to the high hardness value of the deformed brass.

\subsubsection{Impact Energy}

Figure 2 shows the impact energy of the rolled and stress relieved brass as a function of percentage reduction. The impact energy was found to increase steadily with the deformation until 35\% reduction. Further increase in percentage reduction from $35 \%$ to $40 \%$ reduction causes sharp increase in impact energy from $9.5 \mathrm{~J}$ to $21 \mathrm{~J}$ in the case of rolled brass. This is expected as the total energy increase with the amount of cold work [13]. However, the impact energy of rolled brass is lower than that of rolled and stress relieved brass as shown in Figure 2. This is because the rolled brass is subjected to compressive stress at the surface [22] which made it unstable but stress relieved brass after roll deformation contain less dislocations and residual stresses when compared to the rolled brass. Therefore, much energy is required to fracture the stress-relieved brass than the rolled brass when they are both subjected to the same amount of impact.

\subsubsection{Ultimate Tensile Strength}

Figure 3 shows the ultimate tensile strength as a function of percentage reduction of the brass. The ultimate tensile strength was found to increase linearly from $20 \%$ to $25 \%$ reduction and thereafter the ultimate tensile strength remain constant until 30\% reduction was reached where it increases with further \% reduction. Also the rolled and stress-relieved brass had lower ultimate tensile strengths as compared to the brass that was deformed by rolling without stress relieving.It was estimated from Figure 3 that at $25 \%$ reduction, the ultimate tensile strength of rolled brass is about $38 \%$ higher than the rolled and stress relieved brass. However the trend of strength increase in the two brass conditions (rolled and stress relieved) are similar as the ultimate tensile strength increases with percentage reduction. 


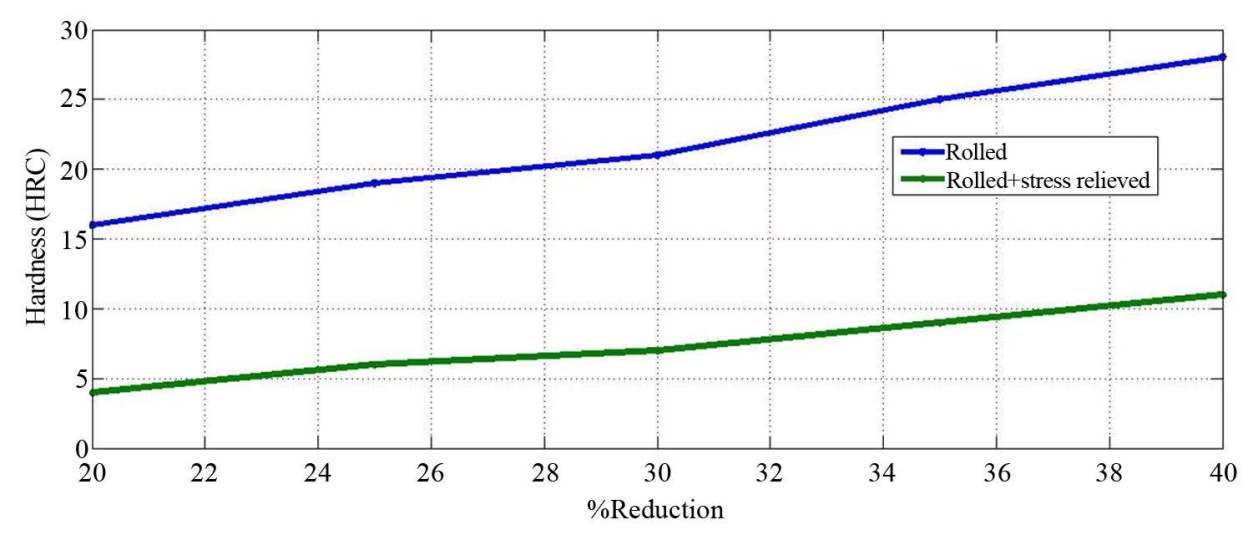

Figure 1. Hardness vs. percentage reduction.

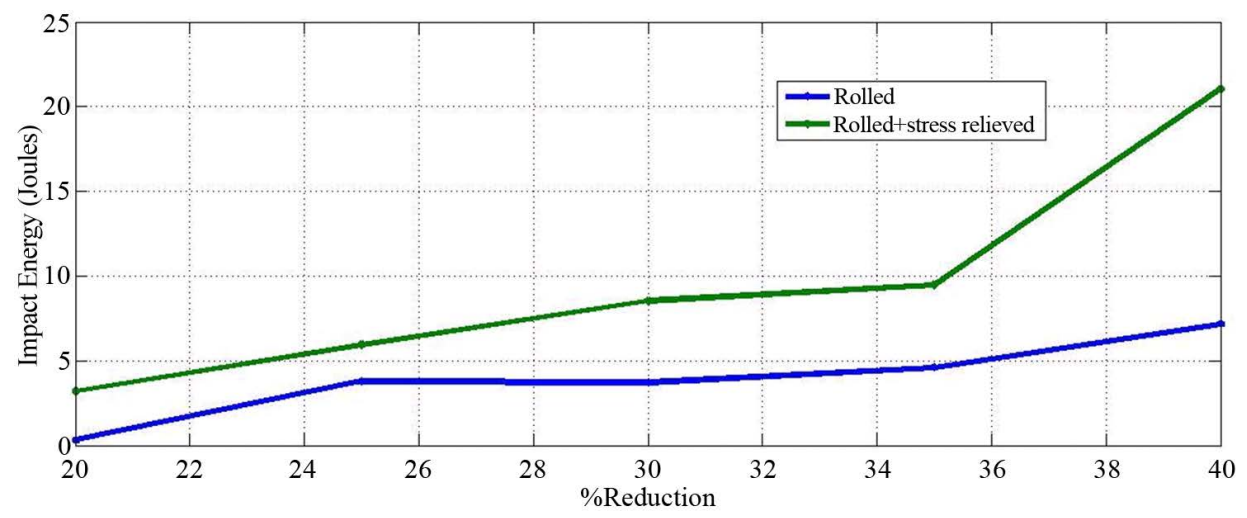

Figure 2. Impact energy vs. percentage reduction.

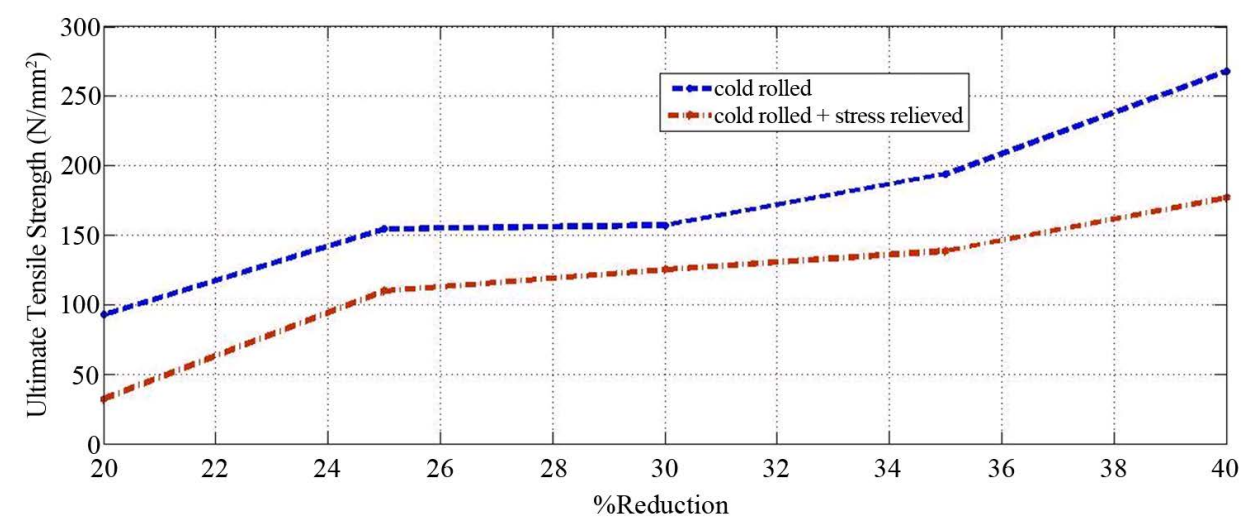

Figure 3. Ultimate tensile strength vs. percentage reduction.

\subsection{Microstructure}

Figure 4 shows the optical micrographs of control sample of brass and the cast brass alloys at various percentage reductions of $20 \%, 25 \%, 30 \%, 35 \%$ and $40 \%$ respectively. The primary alpha phase $(\alpha)$ is the zinc while the Beta phase $(\beta)$ represents the copper phase in the alloy as shown in Figure 4(A). It was observed from Figure 4 that, with increase in percentage cold roll of the brass, the grain sizes are increased and they also become smaller thereby making it hard for the grains to slide over another which has a great effect on the tensile strength as well as the hardness of the brass. Figure 4(A), shows an optical micrograph of the control sample of brass and it may be seen that more-or-less rounded particles of zinc are crystallized, which are surrounded by fine eutectic copper (brighter parts) together with black spots which could be defects introduced during casting of the alloys. 

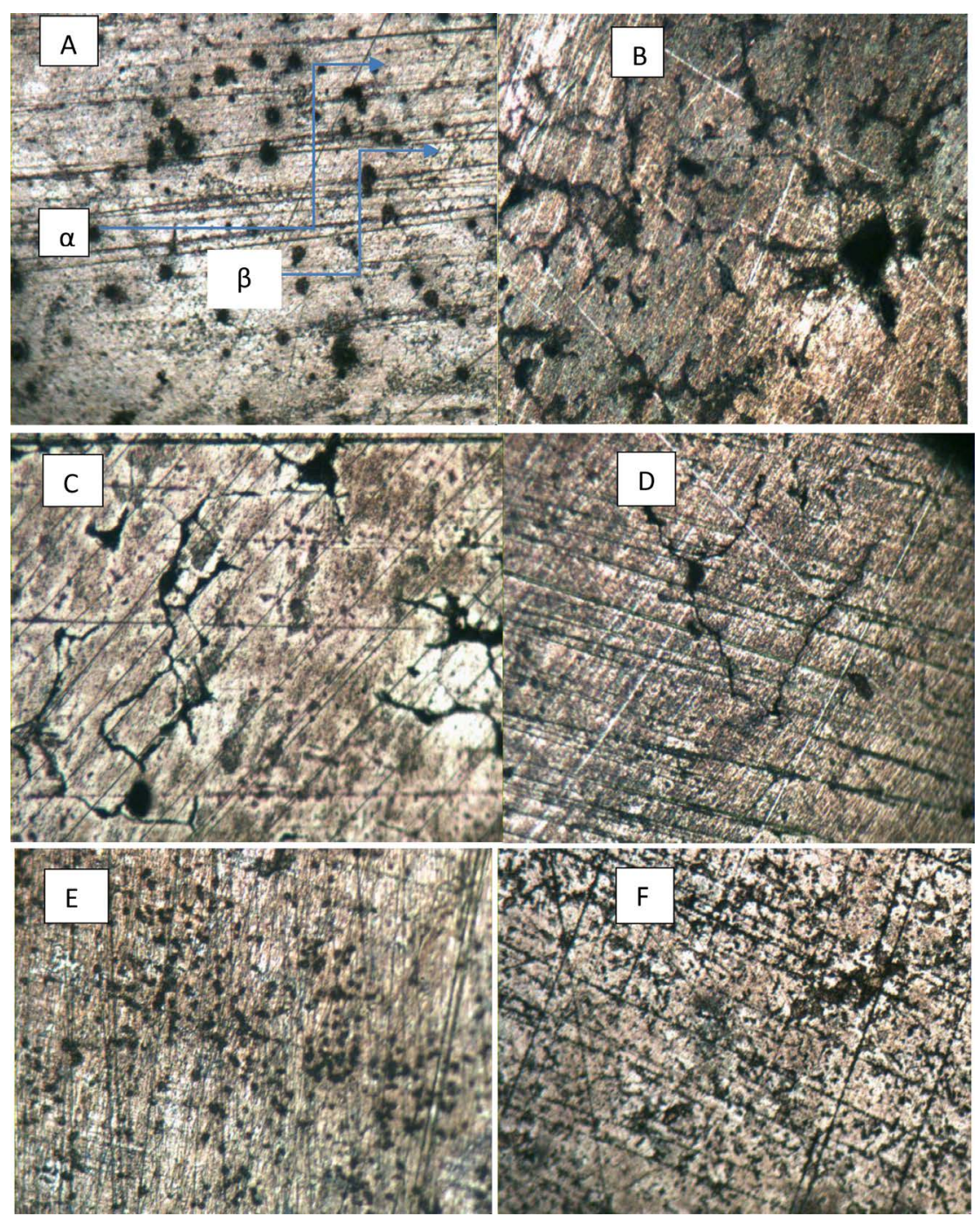

Figure 4. Optical micrograph analysis of: (A) as cast brass AT 200×, (B) $20 \%$ reduction at 200×, (C) 25\% reduction at 200×, (D) 30\% reduction, (E) 35\% reduction and (F) $40 \%$ reduction.

Here, copper has networked structure. It is seen that as the percentage reduction increases, the figures show more refinement of the eutectic copper particles. It may be seen that the degree of refinement of the eutectic copper increased as the percentage cold roll increases. Figure 4(B) shows the optical micrograph of the brass at $20 \%$ reduction which indicated an increase in defects due to mechanical deformation (rolling). Defect such as vacancies and dislocations are introduced as a result of thermo-mechanical processing and this has influence on the mechanical properties of the material. As deformation increased further, Figure 4(C), more defects are introduced which became conspicuous with orientation of the grains. The defects continues to persist even up to 30\% reduction as shown in Figure 4(D). In Figure 4(E), the concentration of defects were found to reduce considerably as a result of randomization of the microstructure during rolling up to $35 \%$ reduction. Again new phase $\beta$ ' evolved from the primary phase ( $\alpha$ and $\beta$ ) as a result of simultaneous rolling and heat treatment up to $450^{\circ} \mathrm{C}$ which lead to two phenomenon of recovery and recrystallization. The grain sizes was also found to reduce after the recrystallization of the new phase.

In Figure 4(F), the defects were almost completely eliminated with the new phase concentration increase substantially. This clearly indicates that the new phase contributed to increase in hardness and strength as indicated in Figure 1 and Figure 3 respectively [22]. Therefore, precipitation strengthening could be the phenomenon accounting for the increase hardness and strength after $30 \%$ reduction rolling and stress relieving. 


\section{Conclusion}

The improvement on the mechanical properties of the brass after cold rolling was due to increasing defects. Annealing the cold rolled brass at $450^{\circ} \mathrm{C}$ was found to reduce the dislocation density as a result of annihilation and polygonization of dislocations and as such the cold rolled samples have higher hardness and strength than the cold rolled and stress relieved samples. At $40 \%$ reduction, the hardness of cold rolled samples was $28 \mathrm{HRC}$ while that of cold rolled and stress relieved sample was 11HRC. Also the strength of cold rolled at $40 \%$ was higher $\left(268.18 \mathrm{~N} / \mathrm{mm}^{2}\right)$ than the cold rolled and stress relieved $\left(176.62 \mathrm{~N} / \mathrm{mm}^{2}\right)$. However, the impact energy increased as the cold rolled samples were stress relieved due to reduction in dislocation density.

\section{Acknowledgements}

The authors wish to thank Mr. Suleiman and Mr. Joel of the Department of Metallurgical and Materials Engineering University of Lagos, Nigeria for the experimental part of this work.

\section{References}

[1] Vilarinho, C., Davim, J.P., Soares, D., Castro, F. and Barbosa, J. (2005) Influence of the Chemical Composition on the Machinability of Brasses. Journal of Materials Processing Technology, 170, 441-447. http://dx.doi.org/10.1016/j.jmatprotec.2005.05.035

[2] Garcia, P., Rivera, S., Palacios, M. and Belzunce J. (2010) Comparative Study of the Parameters Influence the Machinability of Leaded Brasses. Engineering Failure Analyses, 17, 771-776. http://dx.doi.org/10.1016/j.engfailanal.2009.08.012

[3] Bursikova, V., Bursik, J., Navrátil, V. and Milicia, K. (2002) Creep Behavior of Leaded Brass. Materials Science and Engineering, A324, 235-238. http://dx.doi.org/10.1016/S0921-5093(01)01317-X

[4] Kumar, S., Narayanan, T.S.N., Manimaran, A. and Kumar, M.S. (2007) Effect of Lead on the Dezincification Behavior of Leaded Brass in Neutral Acid Acidified 3.5\% NaCl Solution. Materials Chemistry and Physics, 106, 134-141. http://dx.doi.org/10.1016/j.matchemphys.2007.05.030

[5] Taha, M.A., El-Mahallawy, N.A., Hammouda, R.M., Moussa, T.M. and Gheith, M.H., (2012) Machinability Characteristics of Lead Free-Silicon Brass Alloys as Correlated with Microstructure and Mechanical Properties. Ain Shams Engineering Journal, 3, 383-392.

[6] ASM Source Book in Copper and Copper Alloys (1979) Metals Park: American Society for Metals.

[7] Randle, V. and Davies, H. (2002) Evolution of Microstructure and Properties in Alpha-Brass after Iterative Processing. Metallurgical and Materials Transactions A, 33A, 1852-1857. http://dx.doi.org/10.1007/s11661-002-0193-3

[8] Whiting, L.V., Sahoo, M., Newcombe, P.D., Zavadil, R. and Peters, D.T. (1999) Detailed Analysis of Mechanical Properties of SeBiLOYs I and II. AFS Transactions, 182, 343-351.

[9] Saigal, A. and Rohatgi, P. (1996) Machinability of Cast Lead Free Yellow Brass Containing Graphite Particles. AFS Transactions, 104, 225-228.

[10] La Fontaine, A. and Keast, V.J. (2006) Compositional Distributions in Classical and Lead-Free Brasses. Materials Characterization, 57, 424-429. http://dx.doi.org/10.1016/j.matchar.2006.02.005

[11] Peters, D.T. (1997) New Bismuth/Selenium Red Brass Alloys Solve Lead Concerns. Modern Casting, 87, 57-59.

[12] Michels, H.T. (2002) Replacing Lead in Brass Plumbing Castings. Advanced Material and Processes, 75-77.

[13] Verma, A.K., Shingweker, A., Nihichlani, M., Singh, V. and Mukhopadhyay, P. (2013) Deformation Characterization of Cartridge Brass. Indian Journal of Engineering \& Materials Science, 20, 283-288.

[14] Nowosielski, R. (2001) Ductility Minimum Temperature in Selected Mono-Phase, Binary Brasses. Journal of Materials Processing Technology, 109, 142-153. http://dx.doi.org/10.1016/S0924-0136(00)00789-5

[15] Ozgowicz, W., Kalinowska-Ozgowicz, E. and Grzegorczyk, B. (2008) The Influence of the Temperature of Tensile Test on the Structure and Plastic Properties of Copper Alloy Type CuCr1Zr. Journal of Achievements in Materials and Manufacturing Engineering, 29, 123-136.

[16] Nowosielski, R., Sakiewicz, P. and Mazurkiewicz, J. (2006) Ductility Minimum Temperature Phenomenon in as Cast CuNi25 Alloy. Journal of Achievements in Materials and Manufacturing Engineering, 17, 193-196.

[17] Whiting, L., Newcombe, P. and Sahoo, M. (1995) Casting Characteristics of Red Brass Containing Bismuth and Selenium. AFS Transactions, 103, 683-691.

[18] El-Danaf, E., Kalidindi, S.R., Doherty, R.D. and Necker, C. (2000) Deformation Texture Transition in Brass: Critical 
Role of Micro-Scale Shear Bands. Acta Materialia, 48, 2665-2673. http://dx.doi.org/10.1016/S1359-6454(00)00050-1

[19] Konieczny, J. and Rdzawski, Z. (2011) Misorientation in Rolled CuTi4 Alloy. Archives of Materials Science and Engineering, 52, 5-12.

[20] Shaarbaf, M. and Toroghinejad, M.R. (2008) Nano-Grained Copper Strip Produced by Accumulative Roll Bonding Process. Materials Science \& Engineering A, 473, 28-33. http://dx.doi.org/10.1016/j.msea.2007.03.065

[21] Konieczny, J. and Rdzawski, Z. (2012) Structure of Rolled CuTi4 Alloy. Journal of Achievements in Materials and Manufacturing Engineering, 50, 26-39.

[22] Askelend, D.R. and Phule, P.P. (2006) The Science and Engineering Materials. International Student Edition, Toronto, 203-212.

[23] Song, K.H., Kim, H.S. and Kim, W.Y. (2011) Enhancement of Mechanical Properties and Grain Refinement in ECAP 6/4 Brass. Reviews on Advanced Materials Science, 28, 158-161. 